\title{
Charles Bonnet syndrome: characteristics of its visual hallucinations and differential diagnosis
}

\author{
Síndrome de Charles Bonnet: características das alucinações visuais e diagnóstico \\ diferencial
}

Thiago Cardoso Vale 1 Luciene Chaves Fernandes ${ }^{2,3}$, Paulo Caramelli,4

\begin{abstract}
Objective: To present an eight-case serie of patients with Charles Bonnet syndrome (CBS). Method: All patients were initially evaluated by an ophthalmologist and then submitted to a neurologic evaluation with exclusion of alternative psychiatric and neurologic diagnoses. Results: Five patients were male (62.5\%) and the mean age was $52.3+16.0$ years. Two patients suffered from severe myopia and glaucoma, three had retinitis pigmentosa, one had anterior ischemic optic neuropathy, one had age-related macular degeneration and one had toxoplasmic retinochoroiditis. Mean visual acuity in the right eye was 1,12 logMAR and in the left eye 0.57 logMAR. A mean delay of 41.7 months occurred until diagnosis. All hallucinations were complexes and mostly ocurred on a weekly-basis (62.5\%) and lasted for seconds (87.5\%). Conclusions: Physicians who care for low vision patients should be aware of CBS and appropriately diagnose its hallucinations after exclusion of psychiatric and neurologic diseases.
\end{abstract}

Keywords: Charles Bonnet syndrome, visual hallucinations, sensory hallucinations, dementia, low vision.

RESUMO

Objetivo: Apresentar uma série de oito casos da síndrome de Charles Bonnet (SCB). Método: Todos os pacientes foram avaliados por um oftalmologista e por um neurologista, tendo sido excluídos diagnósticos alternativos neurológicos e psiquiátricos. Resultados: Cinco pacientes eram homens (62,5\%) e a média de idade foi de 52,3 $\pm 16,0$ anos. Do total de pacientes: dois tinham miopia grave e glaucoma, três retinose pigmentar, um neuropatia óptica isquêmica anterior, um degeneração macular relacionada à idade e um retinocoroidite toxoplásmica. A acuidade visual média no olho direito foi de 1,12 logMAR e no olho esquerdo foi de 0.57 logMAR. Houve um atraso de 41,7 meses, em média, para o diagnóstico. Todas as alucinações eram complexas, ocorriam, em sua maioria, semanalmente (62,5\%) e duravam segundos (87,5\%). Conclusão: Médicos que lidam com pacientes com baixa visão devem saber distinguir as características peculiares da SCB, após exclusão de doenças neurológicas e psiquiátricas.

Palavras-chave: síndrome de Charles Bonnet, alucinações visuais, alucinações sensoriais, demência, baixa visão.

In elderly patients, hallucinations can be associated with neurologic disorders such as Alzheimer's disease, Parkinson's disease, delirium, sensory and sleep deprivation, and psychosis ${ }^{1}$. Formed and complex visual hallucinations that occur in visually-impaired individuals who are otherwise mentally normal are termed Charles Bonnet syndrome (CBS), in homage to the Swiss philosopher and naturalist Charles
Bonnet (1720-1792) ${ }^{2}$. The prevalence of CBS varies in the literature, ranging from $0.4 \%$ to $15 \%^{1,2,3}$. Its prevalence is certainly underestimated due to low disclosure by patients, lack of knowledge among physicians, variable inclusion criteria and inconsistent depth of questioning. The most common cause of the syndrome is age-related macular degeneration ${ }^{1,2,3}$. However, many other etiologies have

${ }^{1}$ Serviço de Neurologia, Hospital Universitário, Faculdade de Medicina, Universidade Federal de Juiz de Fora, Juiz de Fora MG, Brazil;

${ }^{2}$ Hospital São Geraldo, Universidade Federal de Minas Gerais, Belo Horizonte MG, Brazil;

${ }^{3}$ Sociedade Pan-Americana de Baixa Visão, Belo Horizonte MG, Brazil;

${ }^{4}$ Departamento de Clínica Médica, Faculdade de Medicina, Universidade Federal de Minas Gerais, Belo Horizonte MG, Brazil;

${ }^{5}$ Divisão de Neurologia, Hospital das Clínicas, Universidade Federal de Minas Gerais, Belo Horizonte MG, Brazil.

Correspondence: Paulo Caramelli; Hospital das Clínicas, Departamento de Clínica Médica, Faculdade de Medicina da Universidade Federal de Minas Gerais; Av. Prof. Alfredo Balena, 190 - Sala 246; 30130-100, Belo Horizonte MG, Brasil

Support: Thiago Cardoso Vale and Luciene Chaves Fernandes declare no financial disclosure. Paulo Caramelli is research-funded by Conselho Nacional de Desenvolvimento Científico e Tecnológico (CNPq - Bolsa de Produtividade em Pesquisa) and Fundação de Amparo à Pesquisa do Estado de Minas Gerais (Fapemig).

Conflict of interest: There are no conflicts of interest.

Received 20 December 2013; Accepted 19 January 2014. 
already been implicated and a lesion at any level of the visual system may lead to CBS. Complex images of people are most commonly encountered. Timing and frequency are quite variable and can be episodic, periodic and chronic. They are usually benign, but fear of impeding insanity may occur²,

We describe eight patients with visual impairment and CBS evaluated at our unit and we pinpoint the most useful characteristics that distinguish CBS hallucinations from other etiologies.

\section{METHOD}

Eight patients were enrolled in the study based on initial ophthalmologic consultation. All patients were evaluated by an expert ophthalmologist who performed a standard ophthalmologic consultation with measurement of corrected visual acuity, biomicroscopy of the anterior ocular segment, applanation tonometry and fundoscopy. All patients were diagnosed with an ophthalmologic disease and presented with a decrease in visual acuity. A full neurologic examination was performed by an expert neurologist, including a brief cognitive assessment (Mini-Mental State Examination $^{4}$ and category fluency-animals ${ }^{5}$ ), functional evaluation (Pfeffer's functional activities questionnaire ${ }^{6}$ ), a standardized neuropsychiatric inventory assessment ${ }^{7}$, and the part III of Unified Parkinson's Disease Rating Scale (UPDRS) ${ }^{8}$. Magnetic resonance imaging (MRI; 1.0-Tesla) of the brain was performed in all patients. Patients were diagnosed with CBS based on the detection of a significant visual impairment combined with visual hallucinations considered unreal by the patient. Migraneous aura, epileptic crisis, alcohol withdrawal syndrome, metabolic encephalopathies, narcolepsy, psychiatric disease, peduncular alucinosis and neurodegenerative diseases such as Alzheimer's disease and Lewy body dementia were excluded based on history, brief cognitive assessment, UPDRS scale and brain MRI.

This work has been approved by the Universidade Federal de Minas Gerais' Ethics Committee (0334.0.203.000-10)

\section{RESULTS}

Five patients were male $(62.5 \%)$ and the mean age ( \pm standard deviation) was of $52.3 \pm 16.0$ years. Two patients suffered from severe myopia and cataracts, three had retinitis pigmentosa, one had anterior ischemic optic neuropathy, one had age-related macular degeneration and one had toxoplasmic retinochoroiditis. Except for three patients, the remainder had hypertension, two of them combined with type 2 diabetes mellitus, one of them combined with AIDS and another with alcoholism. Mean visual acuity in the right eye was 1,12 $\operatorname{logMAR}$ and in the left eye 0.57 logMAR. A mean delay of 41.7 months occurred between the onset of visual hallucinations and diagnosis of CBS by the clinicians. All hallucinations were complexes and mostly was on a weekly-basis (62.5\%) and lasted for seconds (87.5\%). Brief cognitive assessment showed mean and standard deviation values for MMSE, Pfeffer's functional activities of daily living, neuropsychiatric inventory assessment, category fluency-animals and UPDRS of, respectively, $24.9 \pm 2.5,2.1 \pm 3.9,8.7 \pm 5.3,13.6 \pm 1.2$ and 1.3 \pm 2.3 . Mean \pm standard deviation of formal years of schooling in our series were $4.7 \pm 2.6$. Table shows the characteristics of the hallucinations of the patients.

Table 1. Main characteristics of visual hallucinations of the series of Charles Bonnet syndrome patients.

\begin{tabular}{|c|c|c|c|c|c|c|c|c|}
\hline Case & Frequency & Duration & Localization & Risk factors & $\begin{array}{l}\text { Position } \\
\text { of eyes }\end{array}$ & Benignity & $\begin{array}{l}\text { Time of } \\
\text { the day }\end{array}$ & $\begin{array}{l}\text { Associated } \\
\text { features }\end{array}$ \\
\hline $\begin{array}{l}1 \text { - } 50 \text { ys, woman } \\
\text { with myopia }\end{array}$ & Daily & Seconds & $\begin{array}{l}\text { Monoocular } \\
\text { (left eye) }\end{array}$ & $\begin{array}{c}\text { Sensory } \\
\text { deprivation }\end{array}$ & Open & Yes & Anytime & None \\
\hline $\begin{array}{l}2 \text { - } 64 \text { ys, man } \\
\text { with macular } \\
\text { degeneration }\end{array}$ & Daily & Minutes & Binocular & $\begin{array}{c}\text { Sensory } \\
\text { deprivation }\end{array}$ & Closed & Yes & Nocturnal & None \\
\hline $\begin{array}{l}3 \text { - } 81 \text { ys, woman, } \\
\text { retinitis pigmentosa } \\
\text { and glaucoma }\end{array}$ & $\begin{array}{c}\text { Weekly (2 days } \\
\text { per week) }\end{array}$ & Seconds & Binocular & $\begin{array}{c}\text { Sensory } \\
\text { deprivation }\end{array}$ & Indifferent & Yes & Nocturnal & None \\
\hline $\begin{array}{l}4 \text { - } 63 \text { ys, man with } \\
\text { cataracts, myopia } \\
\text { and hemianopsia }\end{array}$ & $\begin{array}{c}\text { Weekly (4 days } \\
\text { per week) }\end{array}$ & Seconds & Binocular & $\begin{array}{c}\text { Cerebrovascular } \\
\text { disease }\end{array}$ & Open & Yes & Anytime & Hemiparesis \\
\hline $\begin{array}{l}5 \text { - } 50 \text { ys, woman } \\
\text { with AION }\end{array}$ & $\begin{array}{c}\text { Weekly (3 days } \\
\text { per week) }\end{array}$ & Seconds & Binocular & $\begin{array}{c}\text { Cerebrovascular } \\
\text { disease + Sensory } \\
\text { deprivation }\end{array}$ & Indifferent & Yes & Nocturnal & None \\
\hline $\begin{array}{l}6 \text { - } 35 \text { ys, male with } \\
\text { retinitis pigmentosa }\end{array}$ & $\begin{array}{c}\text { Weekly ( } 2 \text { days } \\
\text { per week) }\end{array}$ & Seconds & Binocular & Sensory deprivation & Open & Yes & Nocturnal & None \\
\hline $\begin{array}{l}7-37 \text { ys, male with } \\
\text { toxoplasmic } \\
\text { retinochoroiditis }\end{array}$ & Daily & Seconds & Binocular & $\begin{array}{c}\text { Sensory deprivation } \\
+ \text { AIDS }\end{array}$ & Indifferent & Yes & Anytime & None \\
\hline $\begin{array}{l}8 \text { - } 39 \text { ys, male with } \\
\text { retinitis pigmentosa }\end{array}$ & $\begin{array}{c}\text { Weekly (5 days } \\
\text { per week) }\end{array}$ & Seconds & Binocular & $\begin{array}{c}\text { Sensory deprivation } \\
+ \text { alcoholism }\end{array}$ & Indifferent & Yes & Nocturnal & None \\
\hline
\end{tabular}

AION: anterior ischemic optic neuropathy. 


\section{DISCUSSION}

Our case series includes eight patients with CBS with low vision secondary to ophthalmologic diseases affecting the retina, cornea and the lens. Visual hallucinations were all complex, with images of animals, persons and bizarre geometric forms. As the definition implies, all patients had intact cognition which was confirmed by brief cognitive screening tests. Epilepsy, migraine, stroke, dementia, parkinsonism and psychiatric diagnoses were excluded based on history and neurologic examination. Most of the hallucinations were weekly and lasting for seconds which might have contributed to the benignity reported by all patients.

The loss of vision in those experiencing CBS is usually bilateral, as our case series demonstrate. Patients do not experience hallucinations in other sensory modalities such as the patients with alcohol withdrawal syndrome. For many patients, the images are easy to identify as they have peculiar characteristics and they are viewed in finer details than real objects. The episodes can last seconds to hours, and the duration may last from days to years. The most common characteristics of visions reported by CBS are: tesellopsia (regular, overlapping patterns), prosopometamorphopsia (facial distortion), dendropsia (branching forms), hyperchromatopsia, polyopia (multiple forms of one image), micropsia and macropsia9. The faces are typically not of individuals known to them and the objects are not of significance to them. These last observations are all consistent with our findings and micropsia, macropsia, prosopometamorphosia and polyopia could be identified in our patients descriptions of the hallucinations. In ffytche and Howard series ${ }^{9}$, tesellopsia ocurred in $74 \%$ and abnormalities of size in $42 \%$ of their patients, of whom $58 \%$ had micropsia. In Brucki et al. ${ }^{10}$ series, tesellopsia, micropsia, prosopometamorphopsia and polyopsia were observed.

Several risk factors for developing CBS have been described. Visual impairment, cerebral damage, social isolation and age are the most important ones. Social or physical isolation, dimly lit conditions, evening hours, and states of drowsiness or relaxation have all been associated with higher rates of recurrent hallucinations in those with CBS. Patients who suffer from a sudden onset of vision loss and sudden onset of visual field loss with cerebral disease are more likely to experience hallucinations than those experiencing more gradual loss of vision ${ }^{1,2}$. Age has been consistently described as one of the main risk factors for developing CBS. The majority of patients with CBS are elderly with a mean age of 70 to 85 years ${ }^{2}$. However, cases have been reported in all age groups. In this case series, the lower mean age of onset (52 years) could be attributed to the consistent questioning of symptoms in the ophthalmologic clinic and widespread knowledge of this study by many ophthalmologists in the institution. Notwithstanding a directed questionnaire, a mean delay in diagnosis of almost 42 months indicates that our patients were younger than the elderly patients described in literature. In another Brazilian case series of CBS, Brucki et al. ${ }^{10}$ described six patients with a mean age of 74.5 years.

The neurophysiology explaining the visual hallucinations in CBS is not clearly elucidated. The currently accepted theory suggests that vision loss leads to visual sensory deafferentation of the visual association cortex, causing disinhibition and later spontaneous firing of the visual cortical regions ${ }^{11}$. The brain activity in the absence of visual input has been compared with what occurs in phantom limb or phantom pain syndromes. Another theory is the release phenomenon, where missing input to primary visual areas causes a disinhibition of visual association areas, contributing to a release of visual hallucinations ${ }^{11}$. Functional MRI studies have found increased activity in the ventral occipital lobe when the hallucinations occur ${ }^{12}$. Single photon emission computed tomography studies showed hyperperfusion areas in the lateral temporal cortex, striatum and thalamus at the exact moment of visual hallucinations, suggesting that these areas might contribute to generate the events ${ }^{13}$.

Many etiologies need to be ruled out in order to confirm the diagnosis of CBS. Fortunately, many of them are readily recognizable by history, physical examination and basic laboratory workup. Healthy individuals may experience hallucinations in the context of intense emotion (stress, grief), sensory deprivation states and hypnopompic and hypnagogic states. Among the pathological causes, toxic-metabolic disorders, hepatic diseases, uremia, metabolic encephalopathy associated with cardiopulmonary insufficiency, endocrine disturbances, vitamin deficiency states and inflammatory and infectious diseases must be ruled out ${ }^{2}$. A thoroughly report on prescription and illicit drugs must be taken as well as if the patient has stopped taking them and might be in a withdrawal syndrome. Neurologic causes such as epilepsy, migraine, stroke, Parkinson's disease, Alzheimer's disease, Lewy body dementia, narcolepsy-cataplexy syndrome and peduncular hallucinosis require a comprehensive neurologic examination and might determine the need for brain imaging. In our series, all patients were submitted to neurologic examination and brain MRI. All patients had low vision due to ophthalmologic compromise, either due to retinal or anterior chamber diseases.

There are many options for treatment and prevention of CBS. If patients are not bothered by visual hallucinations, treatment may not be necessary. Many of them need only education and reassurance of the benign nature of the events, improving their quality of life. Treatment of a reversible cause of visual loss is the first step in managament. There is no current established medical treatment for the hallucinations. Current suggestions arise from case reports 
and case series. Neuroleptics, anticonvulsants, antidepressants and cholinesterase inhibitors have already been tried with favorable results ${ }^{1,2,10}$. Our patients did not require treatment either due to its beningnity or lower frequency. Only one patient refused to receive treatment due polypharmacy currently in use for multiple comorbidities.

Although this case series lack novel findings, we provide a detailed description of fully-evaluated patients and we describe a variety of diagnoses that contrasts with the overall series in literature to date, which focus on the elderly only or on a single eye disease. Hallucinations in the elderly can occur in the context of neurologic, psychiatric, medical and ophthalmologic conditions commonly encountered in clinical practice. Physicians should try to characterize the hallucinations in full detail in order to correctly precise the diagnosis without further delay.

\section{REFERENCES}

1. Teunisse RJ, Cruysberg JR, Hoefnagels WH, Verbeek AL, Zitman FG. Visual hallucinations in psychologically normal people: Charles Bonnet's syndrome. Lancet 1996;347:794-797.

2. Schadlu AP, Schadlu R, Sheperd III JB. Charles Bonnet syndrome: a review. Curr Opin Ophthal 2009;20:219-222.

3. Crane WG, Fletcher DC, Schuchard RA. Prevalence of photopsias and Charles Bonnet syndrome in a low vision population. Ophthalmol Clin North Am 1994;7:143-149.

4. Folstein MF, Folstein SE, McHugh PR. 'Mini-Mental State'. A practical method for grading the cognitive state of patients for the clinician. $J$ Psychiatr Res 1975;12:189-198.

5. Bertolucci PHF, Okamoto IH, Brucki SMD, Siviero MO, Toniolo Neto J, Ramos LR. Applicability of the CERAD neuropsychological battery to Brazilian elderly. Arq Neuropsiquiatr 2001;59:532-536.

6. Pfeffer RI, Kurosaki TT, Harrah $\mathrm{CH} J$ r, Chance JM, Filos S. Measurement of functional acitivities in older adults in the community. J Gerontol 1982;37:323-329.

7. Cummings JL, Mega M, Gray K, Rosenberg-Thompson S, Carusi DA, Gornbein J. The neuropsychiatric inventory: comprehensive assessment of psychopathology in dementia. Neurology 1994;44:2308-2314.

8. Fahn S, Elton R, and members of UPDRS Development Committee. Unified Parkinson's disease rating scale. In: Fahn S, Marsden C, Calne D, Goldstein M (Eds). Recent developments in Parkinson's disease, volume 2. New York, NY, Macmillan, 1987.

9. ffytche DH, Howard RJ. The perceptual consequences of visual loss: "positive" pathologies of vision. Brain 1999;122:1247-1260.

10. Brucki SMD, Takada LT, Nitrini R. Charles Bonnet syndrome: case series. Demen \& Neuropsychol 2009;3:61-67.

11. Hart J. Phantom visions: real enough to touch. Elder Care 1997;9:30-32.

12. ffytche DH, Howard RJ, Brammer MJ, David A, Woodruff P, Williams S. The anatomy of conscious vision: an fMRI study of visual hallucinations. Nat Neurosci 1998;1:738-742.

13. Adachi N, Watanabe T, Matsuda H, Onuma T. Hyperperfusion in the lateral temporal cortex, the striatum and the thalamus during complex visual hallucinations: single photon emission computed tomography findings in patients with Charles Bonnet syndrome. Psychiatry Clin Neurosci 2000;54:157-162. 